4th International Scientific Conference SEC-IASR 2019, Galati, Romania, 7th - 8th June, 2019

\title{
Effectiveness of Sportized Physical Education Based On the Correlation between Physical Qualities and Body Functions
}

Evgeny CHEREPOV, Vitaliy EPISHEV, Ksenia NAUMOVA https://doi.org/10.18662/lumproc/sec-iasr2019/10

How to cite: Cherepov, E., Epishev, V., \& Naumova, K. (2020). Effectiveness of Sportized Physical Education Based On the Correlation between Physical Qualities and Body Functions. In S. Marin \& P. Moisescu (vol. eds.), Lumen Proceedings: Vol. 12. 4th International Scientific Conference SECIASR 2019 (pp. 84-89). Iasi, Romania: LUMEN Publishing House. https://doi.org/10.18662/lumproc/sec-iasr2019/10 


\title{
Effectiveness of Sportized Physical Education Based On the Correlation between Physical Qualities and Body Functions
}

\author{
Evgeny CHEREPOV ${ }^{1 *}$, Vitaliy EPISHEV ${ }^{2}$, Ksenia NAUMOVA ${ }^{3}$
}

\begin{abstract}
Modern challenges require improving the system of youth physical education and providing young people with a wide choice of physical activities. The article deals with the practical provisions for improving the system of physical education designed for young males. The study is based on both systems theory and a synergy approach. It also reveals that certain physical qualities and body functions possess a significant correlation. Therefore, a targeted influence on dominating qualities may indirectly improve associated qualities. The authors propose a method for individualizing training in young males taking into account the correlations existing between physical and functional preparedness and paying special attention to the most developed physical qualities. The experimental group practiced physical education incompliance with basic principles of a PE academic program and extra-curriculum activities making a special emphasis on certain physical activities and the most developed physical qualities. The following activities were proposed to young males: "Team sports", "Track-and-field atbletics", "Fitness aerobics", "Sambo". The study justifies the effectiveness of the PE programs developed in compliance with the correlations between physical qualities and body functions. The authors registered a significant improvement in flexibility, coordination, strength endurance, and speed-strength qualities in the experimental group during a 9-month experiment.
\end{abstract}

Keywords: physical qualities; physical education; individualization; young males; correlation analysis.

\footnotetext{
${ }^{1}$ South Ural State University, Chelyabinsk, Russia

2 South Ural State University, Chelyabinsk, Russia epishevvv@,sussu.ru

3 South Ural State University, Chelyabinsk, Russia naumova.ksenia94@mail.ru 


\section{Introduction}

Modern physical education plays a special role as one of the social factors of influence on the human development process. This is the reason why in the ongoing reforms in the national educational system a special priority is being given to the physical education system transformations [4]. It is physical education that is designed to spearhead a personality development process testable by the relevant qualitative and quantitative progress and physical fitness criteria.

\section{Problem Statement}

One of the key concepts of the physical education service improvement in the national educational system implies the obligatory academic curriculum being combined with elective off-class training models to jointly secure a reasonable physical activity and physical development for the students [5].

The modern educational concept tends to interpret off-class physical training models (additional to regular class education) as supportive for the regular general education programs with their educational progress plans [1], [2], [4]. The off-class educational formats are largely determined by the modern personality-centred educational paradigm albeit is should be mentioned that it is not always clear in real practice what criteria (personality- or body-development-testing) shall be applied by the trainer and trainee for the physical education methods, tools and models selection and design purposes, and whether or not progress in some aspect is associated with regresses in some other aspect [4], [6].

\section{Research Questions/Aims of the research}

Objective of the study was to pilot and test benefits of an elective off-class sportized individualized physical education model with a special emphasis on the correlations of the physical fitness and functionality test rates.

\section{Research Methods}

34 male school children were sampled for the off-class sportized physical education model piloting and testing experiment (run in the 2017-18 school year). At Stage 1 of the study, we rated the physical fitnessand 
functionality of the sample followed by a correlation analysis of the data arrays to find correlations of physical fitness and functionality rates and analyze the body responses to physical trainings with account of the actual physical fitness and morphofunctional characteristics of the sample.

At Stage 2 of the study, the sample was split up into Experimental Group (EG, n=18) and Reference Group (RG, n=16), with the RG trained as required by the regular class physical education program. The EG was trained as provided by the regular physical education program complemented by the elective off-class sportized physical education model, with the trainees engaged in their chosen physical training/ sporting activity for progress of the leading physical qualities, with the options including team sports, athletic gymnastics, fitness aerobics and sambo. The off-class physical education model included 68 training sessions a year $(2$ hours a week) harmonized with and complementing the regular educational programs by specific individual training practices. The training model was customized for the individual physical progress priorities and designed to harmonize the physical and functional progress so as to vary the core physical and functionality rates and at the same time secure progress of other associating qualities and skills.

Every off-class sport training model offered a set of controlled-load exercises designed as follows: by muscle groups: $80 \%$ general and 20\% local workouts; by training load: $25 \%$ maximal and $75 \%$ lower; by load type: $30 \%$ standard evenly rated and $70 \%$ alternating; by training process intensity (power zones): $10 \%$ maximal intensity; $15 \%$ sub-maximal; $55 \%$ moderate; and $20 \%$ low-intensity; by rest type: $75 \%$ full rehabilitation and $25 \%$ incomplete rehabilitation; and by rest regime: $70 \%$ active and $30 \%$ passive rest [3].

\section{Findings and Discussion}

The correlation analysis of the test data arrays found 105 correlation ratios including 53 statistically significant $(\mathrm{p}<0.05-0.001)$ correlations accounting for $55.2 \%$ of the total. This finding may be interpreted as indicative of the fairly sound connections of physical fitness and functionality rates in the junior male sample. The correlation matrix may be split up into the following three groups:

Group 1 presents mostly the anthropometric data including body length, mass and chest circumference at rest and during inspiration. The body length, for instance, was found to be in significant correlation with 
bodymass $(\mathrm{r}=0.57$ with $\mathrm{p}<0.001)$ and chest circumference at rest and during inspiration ( $\mathrm{r}=0.57$ and $\mathrm{r}=0.58$ with $\mathrm{p}<0.001$, respectively).

Group 2 includes mostly physical fitness rates obtained by the following tests: standing long jump; shuttle sprint; wrist dynamometry; prone push-ups; 2-min sit-ups; and flexibility (splits and bridge stretch) tests. All these test rates, with the only exclusion for the spinal flexibility (bridge stretch) test, were found significantly and closely correlated $(\mathrm{p}<0.05-0.001)-$ and this finding shows most of the physical qualities being interdependent in fact. This means that a progress in some physical quality facilitates progress in other qualities. It may be pertinent to make a special emphasis on spinal flexibility in this Group as it showed insignificant correlation with any other physical fitness rate within the Group and, hence, requires special flexibility training practices.

Group 3 includes the respiratory system functionality rates such as vital capacity (VC) and expiratory/ inspiratory reserve volumes (ERV/ IRV), with the VC found significantly correlated with IRV $(r=0.43$; with $\mathrm{p}<0.001)$ and ERV ( $r=0.35$; with $\mathrm{p}<0.001)$. These correlations show that progress in the $\mathrm{VC}$ is associated with progress in other respiratory system functionality rates. It should be noted that $\mathrm{VC}$ was found involved in 14 correlations with the only exclusion for the spinal flexibility $(r=-0.07 ; \mathrm{p}>0.05)$. These data give the reasons to assume that the physical fitness rates are largely determined by the respiratory system functionality in this age group.

The correlation analysis provided an insight into the physical fitness and functionality rates and progress of the sample, with the analytical data being helpful for the age-specific sportized physical education model designs: see Table 1 hereunder.

Having piloted and tested (for 9 months) the elective off-class sportized individualized physical education model, we found a high and significant progress in the EG - as a result of the individualized sportsdriven physical education process customized and managed as required by the progress test rates, with a special emphasis on the leading (most developed) physical qualities used as a driving force for progress in other important physical qualities. Given in Table 1 hereunder are the EG versus $R G$ physical fitness and functionality rates. 
Evgeny CHEREPOV et al. | Lumen Proceedings 12 | SEC-IASR 2019

Table 1.EG versus RG physical fitness and functionality rates

\begin{tabular}{llll}
\hline Tests & RG, $\mathrm{n}=16$ & $\mathrm{EG}, \mathrm{n}=18$ & $\mathrm{P}$ \\
& $\mathrm{X} 1 \pm \mathrm{m} 1$ & $\mathrm{X} 2 \pm \mathrm{m} 2$ & \\
\hline Body length, cm & $176.3 \pm 2.3$ & $176.5 \pm 2.2$ & $>0.05$ \\
Body mass, kg & $63.8 \pm 1.5$ & $64.9 \pm 1.9$ & $>0.05$ \\
Chest circumference, cm & $83.1 \pm 1.8$ & $84.6 \pm 1.1$ & $>0.05$ \\
Standing long jump, cm & $222.1 \pm 5.9$ & $240.4 \pm 4.1$ & $<0.05$ \\
4x9m shuttle sprint, s & $10.1 \pm 0.24$ & $9.6 \pm 0.09$ & $<0.05$ \\
Tap test, c.u. & $40.8 \pm 1.2$ & $40.0 \pm 1.18$ & $>0.05$ \\
Wright wrist dynamometry, kg & $48.0 \pm 2.6$ & $49.1 \pm 1.5$ & $>0.05$ \\
Left wrist dynamometry, kg & $44.1 \pm 3.1$ & $48.2 \pm 1.2$ & $>0.05$ \\
Prone push-ups, reps & $39.13 \pm 3.9$ & $48.7 \pm 1.4$ & $<0.05$ \\
2-min sit-ups, reps & $57.1 \pm 6.01$ & $74.4 \pm 4.3$ & $<0.05$ \\
& & & \\
Vital capacity (VC), ml & $4350 \pm 175$ & $4720 \pm 111$ & $<0.05$ \\
Breath-holding tests during expiration, s & $74.0 \pm 6.8$ & $87.3 \pm 5.2$ & $<0.05$ \\
Breath-holding tests during inspiration, s & $44.2 \pm 6.2$ & $63.5 \pm 4.8$ & $<0.05$ \\
Hip flexibility, c.u. & $-9.88 \pm 3.2$ & $3.1 \pm 0.9$ & $<0.05$ \\
Spinal flexibility, c.u. & $38.63 \pm 2.0$ & $40.56 \pm 1.0$ & $>0.05$ \\
\hline
\end{tabular}

\section{Conclusions}

The study data and correlation analysis of the physical fitness and functionality rates in the junior male sample showed a wide variety of physical fitness, respiratory system functionality and anthropometric characteristics being in close and significant correlations. The study data demonstrated benefits of the elective off-class sportized physical education model as verified by the high and significant physical and functional progress of the EG versus RG for the relatively short period of time. 


\section{References}

[1] Bal'sevichVK. ,Lubysheva LI. Sports oriented physical education: educational and social aspects. Teoriyaipraktikafiz. Kultury. 2003; 5: 19-22.

[2] Lubysheva LI. Physical and sports culture: content, interrelations and dissociations. Teoriya i praktika fiz. kultury, 2002; 3:11-14.

[3] Platonov VN. Training System of Athletes in Olympic Sports: General Theory and its Practical Application. Kiev: Olimpiyskaya literatura publ.; 2004. 808 p.

[4] Cherepov EA. Strength building in young senior male pupils based of education-training module. Vestnik YuUrGU. Ser. Obrazovanie, zdravookhranenie, fizicheskayakultura. 2014; 14(2): 7-13.

[5] Lubysheva LI, Cherepov EA. Justification of Effectiveness of a Designed Health-Forming Education Space in School Based on Sportization of Physical Education. Human. Sport. Medicine. 2016; 16(2): 52-61. (in Russ.) DOI: $10.14529 /$ hsm160205.

[6] Tremarche PV, Robinson EM, Graham LB. Physical Education and Its Effect on Elementary Testing Results. Physical Educator. 2007; 64(2): 58-64. 